(2) Open Access Full Text Article

\title{
Active-Ingredient Screening and Synergistic Action Mechanism of Shegan Mixture for Anti-Asthma Effects Based on Network Pharmacology in a Mouse Model of Asthma
}

\author{
Qing $Y e^{1, *}$ \\ Qiqiang Zhang ${ }^{1} *$ \\ Huijuan Yao',* \\ Ajing $X u^{\prime}$ \\ Yan Liu' \\ Jia $\mathrm{Qi}^{\mathrm{I}}$ \\ Hai Zhang $\mathbb{D}^{2}$ \\ Jian Zhang'
}

'Department of Pharmacy, Xinhua Hospital, Affiliated to Shanghai Jiao Tong University, School of Medicine, Shanghai, 200092, People's Republic of China;

${ }^{2}$ Department of Pharmacy, Shanghai First Maternity and Infant Hospital, Tongji University School of Medicine, Shanghai, 201204, People's Republic of China

*These authors contributed equally to this work
Correspondence: Jian Zhang Department of Pharmacy, Xinhua Hospital, Affiliated to Shanghai Jiao Tong University, School of Medicine, 1665

Kongjiang Road, Yangpu District, Shanghai, 200092, People's Republic of China

Tel/Fax +86 2I-25077I50

Email zhangjian@xinhuamed.com.cn

Hai Zhang

Department of Pharmacy, Shanghai First Maternity and Infant Hospital, Tongji University School of Medicine, 2699 High

Tech West Road, Pudong New Area,

Shanghai, 201204, People's Republic of

China

Tel/Fax +86 2I-2026I 401

Email zhxdks2005@I26.com
Background: Shegan Mixture (SGM) is a traditional Chinese medicine that has antiinflammatory and therapeutic effects on asthma. However, its active ingredients and combined action mechanism have not been fully elucidated so far. The purpose of this study was to screen the effective ingredients and targets and elucidate the synergistic action mechanism of SGM in asthma mice using the network pharmacological approach.

Methods: A mouse model of asthma model was used in this study. Mice were orally administered SGM at three doses for 4 weeks and the effect of SGM on asthma was evaluated. The active ingredients and their targets of SGM were identified by searching databases, such as Traditional Chinese Medicine Systems Pharmacology Database (TCMSP). The main active ingredients were selected with parameters OB and DL. The synergistic action mechanisms of SGM in asthma were studied through key active ingredient-target interaction network and verified using surface plasmon resonance assay (SPR).

Results: SGM exerts anti-asthmatic effects by reducing lung tissue damage and inflammatory factors (IFN- $\gamma$, IL-4, IL-5, and IL-13) in asthmatic mice. Twenty ingredients and 45 related proteins were selected as potential nodes using enrichment analysis and network analysis. Inflammation and smooth muscle regulation-related pathways were considered to be the main pharmacological mechanisms of SGM in the treatment of asthma. Especially, 5 molecule-target pairs (including 3 ingredients and 4 proteins) were well docked with each other and the SPR assay revealed that glabridin-PTGS2 had good binding with $44.5 \mu \mathrm{M} \mathrm{Kd}$ value.

Conclusion: SGM exerts the synergistic anti-asthma effects by virtue of reducing lungtissue damage and inflammatory factors in asthmatic mice, which explains the theoretical basis for the traditional Chinese medicine, SGM, to treat asthma. Our study thus sheds light on a variety of options including Chinese medicine that could potentially be used in the clinical treatment of asthma.

Keywords: Shegan mixture, asthma, network pharmacology, surface plasmon resonance, traditional Chinese medicine

\section{Introduction}

Asthma is a chronic inflammatory disorder of the airways. As one of the most common respiratory diseases, it affects the lives of approximately 339.4 million people worldwide. ${ }^{1}$ Its main symptoms include respiratory manifestations such as wheezing, difficulty in breathing, chest tightness, and coughing and is accompanied 
by expiratory airflow limitation. ${ }^{2}$ In this study, we focused on certain aspects of asthma, namely, episodic airway narrowing, increased reactivity, and pharmacological and spontaneous reversibility. During local inflammation, the airway smooth muscle cells proliferate and migrate, and the reticular basement membrane thickens, which promotes bronchospasm and consequently changes the structure and function of lung tissue. ${ }^{3,4}$ It appears that alleviating the inflammation and relaxing the airway smooth muscle could be crucial treatment modalities in the management of asthma.

Currently, commonly used drugs in the therapy of asthma include inhaled short-acting $\beta 2$ agonists, inhaled corticosteroids (ICSs), inhaled long-acting $\beta 2$ agonists, theophylline and leukotriene receptor antagonists. Among these, inhaled $\beta 2$ agonists and ICSs can relax the airway smooth muscle and inhibit inflammatory, respectively. ${ }^{5}$ It is worth noting that the use of ICSs has decreased the mortality rate in most countries over the past few decades and most deaths caused by asthma are preventable. ${ }^{6}$

Asthma-related deaths occur even in developed countries. ${ }^{7}$ According to a prospective cohort study in
Northern Europe that was based on questionnaires, the remission rate was about $20 \%$ after 10 years of followup in participants with asthma before or after the age of 20 years. ${ }^{8}$ Although ICSs are safer than orally administered drugs, they can still change the abundance of bacteria in the bronchi after long-term therapy. ${ }^{9}$ ICSs are also associated with the risk of asthma exacerbation after withdrawal. ${ }^{10}$ It is now known that inhaled $\beta 2$ agonists can promote eosinophilic airway inflammation ${ }^{11}$ and worsen asthma. ${ }^{12}$ Additionally, the overuse of potent inhaled $\beta 2$ agonists and no controller medications, such as ICSs, even increases asthma mortality, ${ }^{13,14}$ which is a huge risk during drug therapy.

Shegan Mixture (SGM), a traditional Chinese medicine (TCM) formula, is constructed according to the TCM thesis. The causes of asthma are attributed to external cold and internal fluid retention, phlegm-heat obstructing the lungs, phlegm-dampness in the lungs, and phlegm obstruction due to qi weakness. SGM comprises nine herbs, including Belamcandae Rhizome (Shegan, BR), Ephedra Herba (Mahuang, EH), Scutellariae Radix (Huangqin, SR), Peucedani Radix (Qianhu, PR),

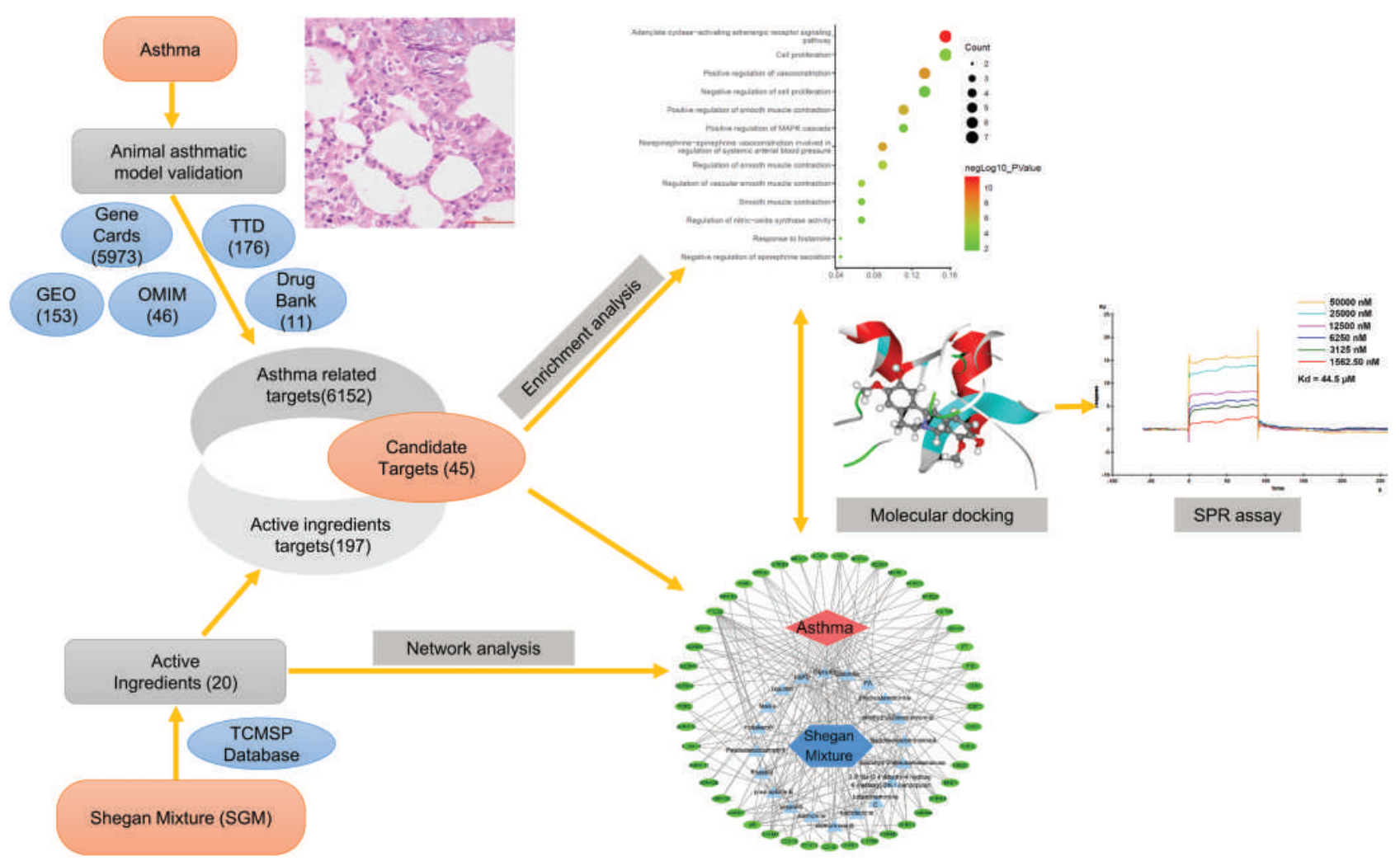

Figure I Flowcharts of network pharmacology analysis. Left: animal model validation and summary of the identification of candidate targets with therapeutic effects against asthma and active ingredients. Right: summary of the pharmacological mechanisms of SGM using enrichment analysis and the determination of the key compound-target pairs using molecular docking and surface plasmon resonance (SPR) assay. 
Amygdalus Communis Vas (Xingren, ACV), Bombyx Batryticatus (Jiangcan, BB), Rorippa Indica (Hancai, RI), Cicadae Periostracum (Cantui, CP), and Stemonae Radix (Baibu, SR). In clinical practice, it has been used in the management of chronic asthma for ten years and has also been approved by the Shanghai Food and Drug Administration (No.180450, Shanghai) to treat bronchial inflammation. It is associated with fewer adverse reactions compared to the drugs routinely used in clinical practice. In a randomized controlled trial, compared with salbutamol and montelukast, the prescription of traditional Chinese medicine containing SGM was effective in controlling the symptoms of patients with asthma. ${ }^{15}$

However, there is no systematic elucidation yet of the anti-asthma components, effects, and pharmacological mechanisms of SGM. Therefore, the present study aims to delineate the key effective ingredients and possible pharmacological mechanisms of the anti-asthma effects of SGM using network pharmacology. Additionally, its pharmacological functions are also identified in a mouse model of asthma. The flow chart of the whole study is shown in Figure 1.

\section{Materials and Methods Ethics Statement}

A mouse model was used in this study. All experimental procedures complied with the Guidelines on the Care and Use of Laboratory Animals (National Institutes of Health Publication no.85-23, revised 1996) and were approved by the Institutional Animal Care and Use Committee of the Shanghai Jiaotong University, School of Medicine [Shanghai, China, NO. SYXK (Shanghai) 2018-0038], and authorized by Xinhua Hospital, affiliated to Shanghai Jiao Tong University, School of Medicine (Shanghai 200,092, China)

\section{Reagents and Materials}

SGM, batch No. 20,190,620, was obtained from Shanghai Fangxin Technology (Shanghai, China), in which each $\mathrm{mL}$ was equivalent to $1.25 \mathrm{~g}$ of the crude drug. Ovalbumin was purchased from Sigma (Cambridge, MA, USA). IL-4, IL-5, IL-13, and IFN- $\gamma$ ELISA kits were purchased from Biovision Biotechnology (Milpitas, CA, USA). The standard compound, glabridin, was purchased from Shanghai Standard Technology (Shanghai, China). The protein, PTGS2, was obtained from Proteintech (Chicago, IL,
USA). The ultrasonic nebulizer was purchased from BEI JING YSKD Biotechnology (Beijing, China). And the RT-6100 Microplate Reader was purchased from Rayto Life and Analytical Sciences (Shenzhen, China).

\section{Evaluation of Anti-Asthma Effects of SGM}

Female BALB/c mice weighing $20 \pm 2.0 \mathrm{~g}$ were purchased from Shanghai SLAC Laboratory Animal Co., Ltd [(Shanghai, China), SCXK 2017-0005 (Shanghai)]. All animals were raised in an SPF environment of the Laboratory Animal Center of Xinhua Hospital affiliated to the Shanghai Jiaotong University School of Medicine. The temperature was maintained at $25 \pm 2^{\circ} \mathrm{C}$ and relative humidity at $45 \pm 5 \%$. Mice were allowed access to water and food ad libitum. According to the clinical study and drug instructions of SGM in asthma patients, ${ }^{15,16}$ the daily dosage of $\mathrm{SGM}$ is $30 \mathrm{~mL}$ for the treatment of asthmas.

Table I Pathological Scoring Criteria for Lung Injury

\begin{tabular}{|c|c|c|c|}
\hline Score & $\begin{array}{l}\text { Eosinophil } \\
\text { Infiltration Around } \\
\text { Trachea and } \\
\text { Bronchus }^{\mathrm{a}}\end{array}$ & Edema $^{b}$ & $\begin{array}{l}\text { Airway } \\
\text { Epithelial } \\
\text { Injuryc }^{c}\end{array}$ \\
\hline 0 & Normal & Normal & Normal \\
\hline I & $\begin{array}{l}\text { Slight cell infiltration, no } \\
\text { histopathological } \\
\text { changes }\end{array}$ & Mild diffuse & Mild cell loss \\
\hline 2 & $\begin{array}{l}\text { Mild to moderate cell } \\
\text { infiltration, mild } \\
\text { histopathological } \\
\text { changes }\end{array}$ & $\begin{array}{l}\text { Moderate } \\
\text { alveolar } \\
\text { and } \\
\text { bronchial }\end{array}$ & Mild cell loss \\
\hline 3 & $\begin{array}{l}\text { Moderate cell } \\
\text { infiltration, mild } \\
\text { histopathological } \\
\text { changes }\end{array}$ & $\begin{array}{l}\text { Regional or } \\
\text { focal }\end{array}$ & $\begin{array}{l}\text { Moderate cell } \\
\text { loss }\end{array}$ \\
\hline 4 & $\begin{array}{l}\text { Moderate to high cell } \\
\text { infiltration, obvious } \\
\text { histopathological } \\
\text { changes }\end{array}$ & Obvious & $\begin{array}{l}\text { Moderate cell } \\
\text { loss }\end{array}$ \\
\hline 5 & $\begin{array}{l}\text { High cell infiltration, } \\
\text { significant } \\
\text { histopathological } \\
\text { changes }\end{array}$ & $\begin{array}{l}\text { Pneumonia- } \\
\text { like }\end{array}$ & $\begin{array}{l}\text { Epithelial cell } \\
\text { metaplasia, } \\
\text { mucous cell } \\
\text { hyperplasia }\end{array}$ \\
\hline
\end{tabular}

Notes: ${ }^{a}$ Light, medium, and heavy cell infiltration refers to 5-19 cells per high-back lens, 20-39, 40 or more. ' Mild edema refers to the swelling of cells, the intercellular space is slightly wider, and occasionally a small amount of exudate; moderate refers to the intercellular space is wider than 0.5 cell diameter and there is more exudate. 'Mild cell loss refers to occasional interruption of the epithelium under high-back microscope and less than 5 cell diameters; moderate refers to the long distance of epithelial interruption and more than 5 cell diameters. 
Then, the dosage for human is converted based on the body surface area method to mouse dosage, ${ }^{17}$ and the mouse dosage is calculated to be $0.05 \mathrm{~mL}$ per $10 \mathrm{~g}$. In addition, the production batch of SGM shows that $1.25 \mathrm{~g}$ crude drug is equal to $1 \mathrm{~mL}$, so the dose for mice is $6.25 \mathrm{~g} /$ $\mathrm{kg}$ as the low-dose group. They were divided into six groups, including a control group, asthmatic model group, SGM high-dose group $(25.0 \mathrm{~g} / \mathrm{kg})$, SGM mediumdose group (12.5 g/kg), SGM low-dose group $(6.25 \mathrm{~g} / \mathrm{kg})$, and dexamethasone group $(0.5 \mathrm{mg} / \mathrm{kg})$, with nine mice in each group.

Start asthma modeling when mice are eight weeks old. To activate the airway response in mice, briefly, mice were injected intraperitoneally with $0.2 \mathrm{~mL}$ of sensitizing solution on $0 \mathrm{~d}$ and $8 \mathrm{~d}$, and were challenged with $1 \%$ OVA nebulized inhalation from the 15 th day. ${ }^{18}$ Nebulized inhalation lasted for 30 min once a day for 6 weeks. From the 15th day, each group was given different doses of Shegan mixture, dexamethasone and normal saline by intragastric administration 1 hour before each atomization. For sensitizing solution, add $10 \mathrm{mg}$ OVA to $1 \mathrm{~mL}$ normal saline. After fully dissolving, add $0.4 \mathrm{~mL}$ to $9.6 \mathrm{~mL}$ of normal saline and mix well. Take this solution and mix with an equal volume of aluminum hydroxide gel. Shake it for 30 minutes before use. The stimulation was considered successful if the mice were restless, short of breath, displayed limpness of limbs, and incontinence after stimulation. After 6 weeks, all mice were anesthetized using pentobarbital sodium (50 $\mathrm{mg} / \mathrm{kg}$ i.p.). Their abdominal cavity was quickly opened and blood collected from the abdominal aorta. Then, whole blood samples were centrifuged at $1000 \times \mathrm{g}$ for 20 minutes. The content of IL-4, IL-5, IL-13, IFN- $\gamma$ in the supernatant were determined using Elisa kits, according to manufacturer's instructions. Absorbance was determined at $450 \mathrm{~nm}$ using a microplate reader. The relative concentration was calculated using a standard curve and each experimental group had triplicate wells. Besides, the whole experiment was performed three times.

The lung tissue was excised and stored in cold Hanks' balanced salt solution (HBSS) that did not contain $\mathrm{CaCl}_{2}$ or $\mathrm{MgCl}_{2}$. Next, samples were fixed in $4 \%$ paraformaldehyde for about 24 hours and embedded in paraffin. After coagulation, cross-sections $(5 \mu \mathrm{m})$ were subjected to hematoxylin and eosin (H\&E) staining. The evaluation criteria of lung injury index are shown in Table $1 .{ }^{19}$

\section{Screening Active Ingredients of SGM}

Based on the Latin name of each ingredient, the active ingredients of SGM were screened using the Traditional Chinese Medicine Systems Pharmacology (TCMSP) database (http:// tcmspw.com/tcmsp.php, downloaded on January 20, 2021),
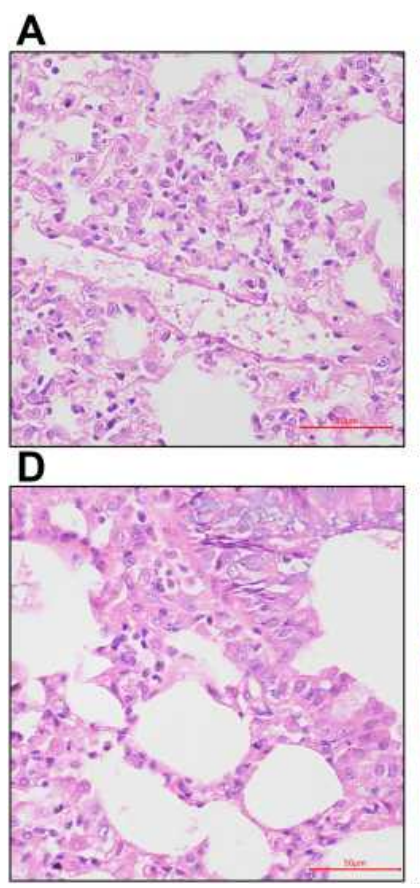

B
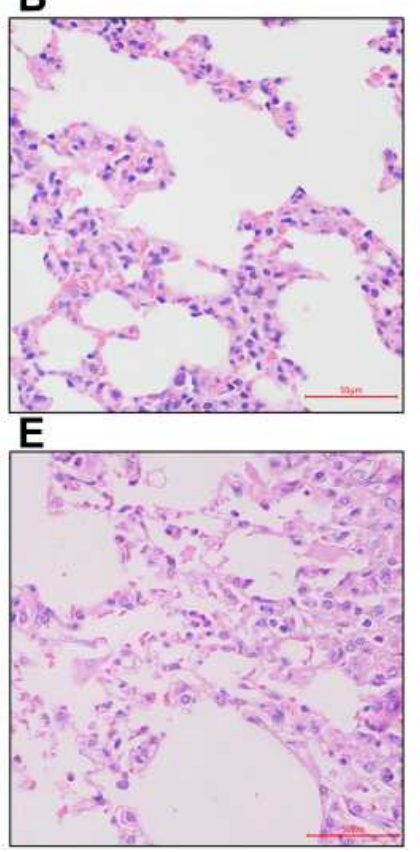

C

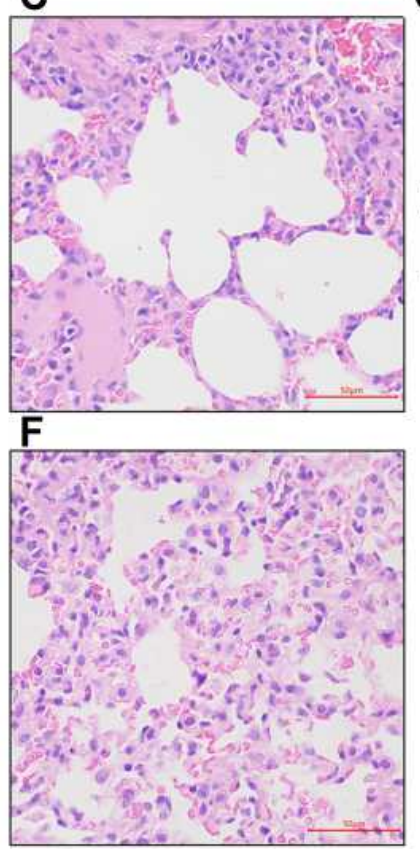

G

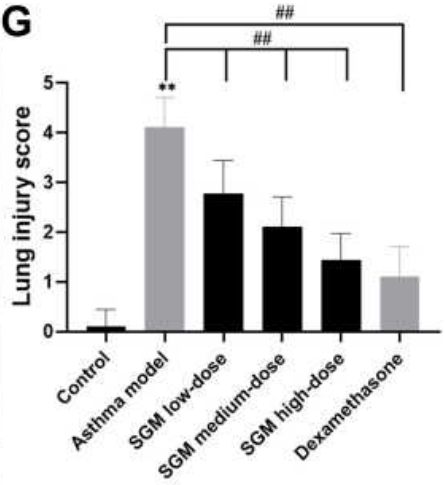

Figure 2 Representative images of hematoxylin and eosin staining in asthma model stimulated with I\% ovalbumin for 6 weeks and with or without SGM administration using ultrasonic spray inhalation for 4 weeks. (A) control group; (B) asthma model group; (C) asthma model with low-dose SGM group; (D) asthma model with medium-dose SGM group; (E) asthma model with high-dose SGM group; (F) asthma model with dexamethasone. (G) Lung injury score. Scale bar $50 \mu \mathrm{m}$. Data are mean \pm S.E.M. $\mathrm{n}=8$. $* *$ $p<0.0$ I versus control group; \# $p<0.01$ versus model group. 
A

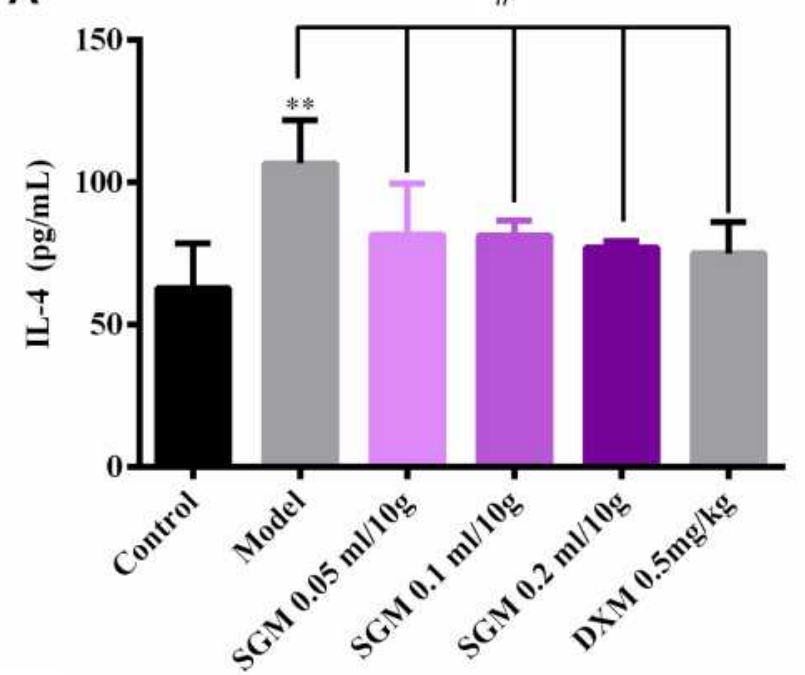

C

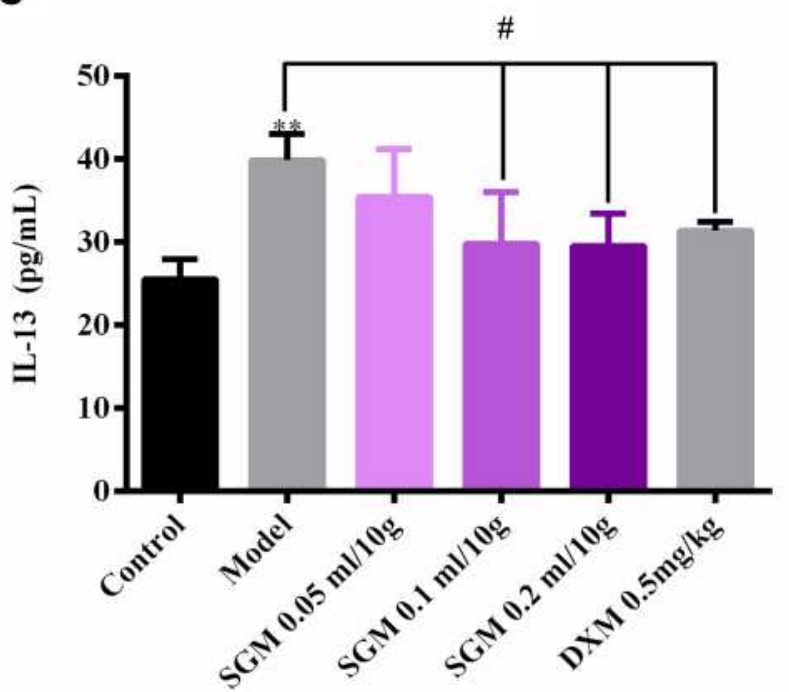

B

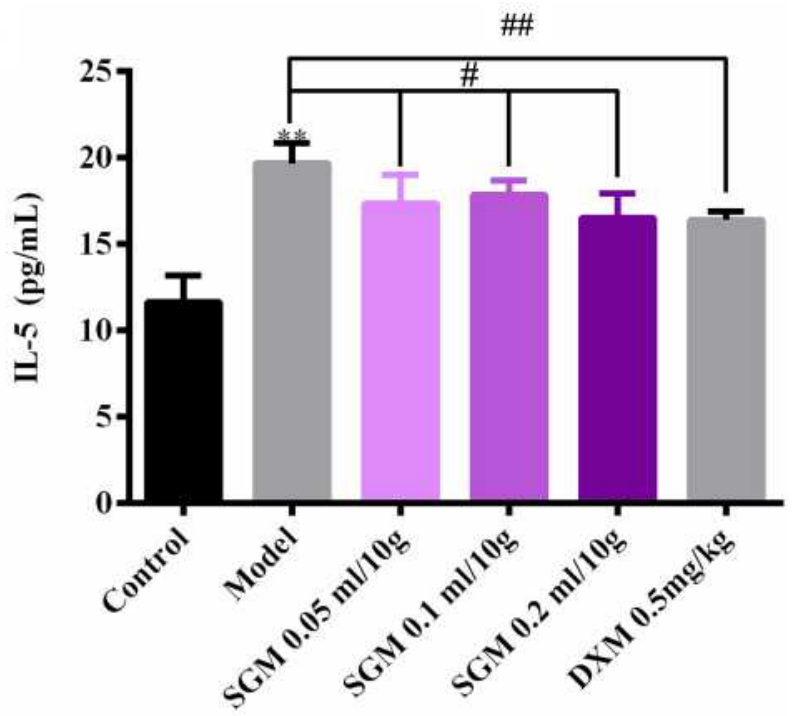

D

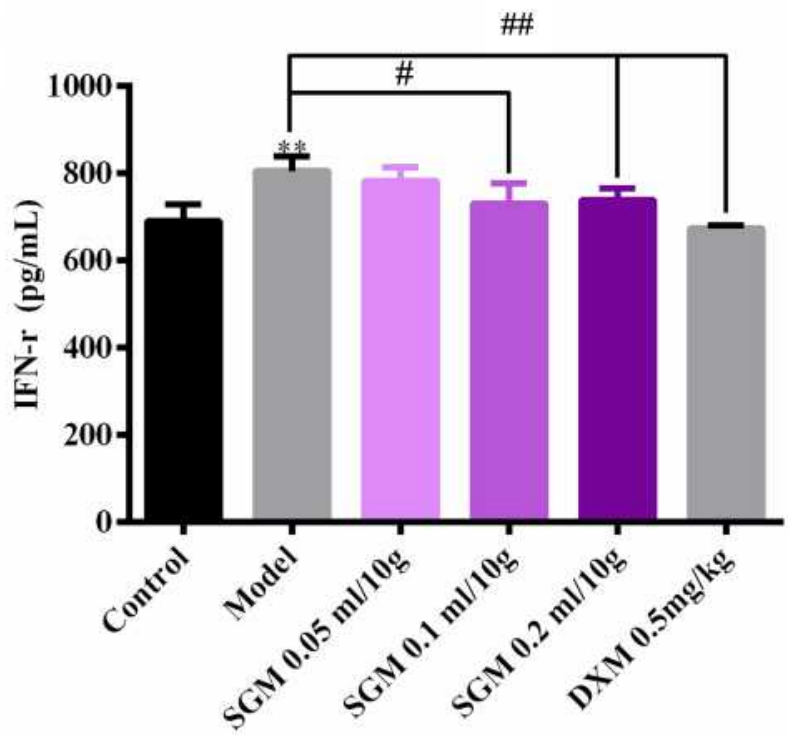

Figure 3 ELISA using blood serum of rats from the asthma model stimulated with I\% ovalbumin for 6 weeks and with or without SGM administration using ultrasonic spray inhalation for 4 weeks. (A) IL-4; (B) IL-5; (C) IL-I3; (D) IFN- $\gamma$. Data are mean \pm S.E.M. $n=3-4$. $* * p<0.0$ I versus control group; \#p<0.05, \#p<0.0I versus model group.

as well as previously reported literature. ${ }^{20}$ In addition, important parameters such as oral bioavailability (OB), druglikeness (DL), molecular weight (MW), intestinal epithelial permeability (Caco-2), and drug half-life (HL) were used in this study. ${ }^{20,21}$ It is worth noting that among all these descriptive indicators, OB and DL are the two most important indicators for evaluating and identifying candidate compounds. $^{22-24} \mathrm{OB}$ refers to the speed and extent at which the drug in the preparation is absorbed into the human circulation. Drugs or ingredients with a higher OB value mean that they are more easily absorbed into the body to interact with potential targets and serve as therapeutic drugs. DL can be used to optimize pharmacokinetics and drug properties. The higher the DL, the more likely it is to become a drug. ${ }^{25,26}$ Based on $\mathrm{OB}>30 \%$ and $\mathrm{DL} \geq 0.18$, the active ingredients were determined for subsequent research. In addition, we searched the PubMed, Embase, WangFang, and CNKI databases with the active ingredients and asthma as keywords, ranked the retrieved articles, and screened out the possible key active ingredients. We also obtained the Smile structures of the ingredients from the PubChem database.

\section{Potential Targets for Active Ingredients and Asthma}

The ingredient-related targets were predicted by inputting to TCMSP database. Known asthmatic treatment 
targets were identified using four widely used databases, including the DrugBank database (https://www.drug bank.ca/, downloaded on January 20, 2021), Online Mendelian Inheritance in Man Database OMIM (http:// www.omim.org/, downloaded on January 20, 2021), Human Gene Database GeneCards (https://www.gene cards.org/, downloaded on January 20, 2021), and Therapeutic Target Database TTD (http://db.idrblab.net/ ttd/, downloaded on January 20, 2021). In order to expand the scope of screening, using a cut-off value of $\mathrm{P}<0.05$ and fold change $|\mathrm{FC}| \geq 2.0$, the differentially expressed genes (DEGs) between healthy individuals and asthmatic patients were extracted from the microarray data, GSE35643, in the Gene Expression Omnibus (GEO; http://www.ncbi.nlm.nih.gov/geo/) database. ${ }^{27}$ After eliminating duplicates, these ingredient-related targets and DEGs were selected as genes related to asthma. After getting an intersection, the potential targets related to both ingredients and asthma were selected.

\section{Protein-Protein Interaction (PPI)}

To screen key protein targets with therapeutic effects against asthma, a PPI was performed as reported in a previous study. ${ }^{28}$ Briefly, potential targets related to both ingredients and asthma were analyzed using the STRING database (http://string-db.org/, downloaded
January 22, 2021), which is a database of known and predicted interactions between proteins. To evaluate PPI, four types of confidence scores were used, including highest (0.9), high (0.7), medium (0.4), and low (0.1), and potential therapeutic targets with scores $\geq 0.9$ were selected for further analysis.

\section{Network Construction and Analysis}

To analyze the relationship between ingredients and these potential therapeutic targets, a network of "ingredienttarget" were established using Cytoscape 3.8 software. Some of these analysis parameters, such as degree, were used to evaluate the importance of nodes and were calculated using NetworkAnalyzer program. When the degree value of a node exceeds twice the average value of all nodes, the node was considered to play a key role in the network.

\section{Enrichment Analysis of Potential Therapeutic Targets}

By inputting all potential therapeutic targets into the DAVID server (https://david.ncifcrf.gov/, v6.8), online Gene Ontology (GO) term enrichment analysis and KEGG (Kyoto Encyclopedia of Genes and Genomes) enrichment analysis were conducted to identify the biological functions of these targets. Meanwhile, the

Table 2 Information of 20 Potential Ingredients Screened from TCMSP

\begin{tabular}{|c|c|c|c|c|}
\hline No. & Molecule Name & Herb Source & OB (\%) & DL \\
\hline I & Glycyrol & Amygdalus Communis Vas & 90.78 & 0.67 \\
\hline 2 & L-SPD & Amygdalus Communis Vas & 87.35 & 0.54 \\
\hline 3 & Stemonine & Stemonae Radix & 81.75 & 0.72 \\
\hline 4 & Phaseol & Amygdalus Communis Vas & 78.77 & 0.58 \\
\hline 5 & Stemoninine B & Stemonae Radix & 74.77 & 0.73 \\
\hline 6 & FA & Bombyx Mori L. & 68.96 & 0.71 \\
\hline 7 & Dihydro-stemoninine & Stemonae Radix & 68.01 & 0.72 \\
\hline 8 & Liquiritin & Amygdalus Communis Vas & 65.69 & 0.74 \\
\hline 9 & Peucedanocoumarin II & Peucedani Radix & 63.48 & 0.53 \\
\hline 10 & Bisdehydro-stemoninine A & Stemonae Radix & 62.64 & 0.68 \\
\hline 11 & Suchilactone & Stemonae Radix & 57.52 & 0.56 \\
\hline 12 & Nodakenin & Peucedani Radix & 57.12 & 0.69 \\
\hline 13 & Sesamin & Stemonae Radix & 56.55 & 0.83 \\
\hline 14 & Mairin & Amygdalus Communis Vas & 55.38 & 0.78 \\
\hline 15 & Tubero-stemonine $\mathrm{C}$ & Stemonae Radix & 55.34 & 0.74 \\
\hline 16 & Glabridin & Amygdalus Communis Vas & 53.25 & 0.47 \\
\hline 17 & 3,3'-bis-(3,4-dihydro-4-hydroxy-6-methoxy)-2H-I-benzopyran & Stemonae Radix & 52.11 & 0.54 \\
\hline 18 & Didehydrotubero-stemonine & Stemonae Radix & 51.91 & 0.74 \\
\hline 19 & Praeruptorin E & Peucedani Radix & 51.22 & 0.66 \\
\hline 20 & Bisdehydroneotubero-stemonine & Stemonae Radix & 51.14 & 0.74 \\
\hline
\end{tabular}


A

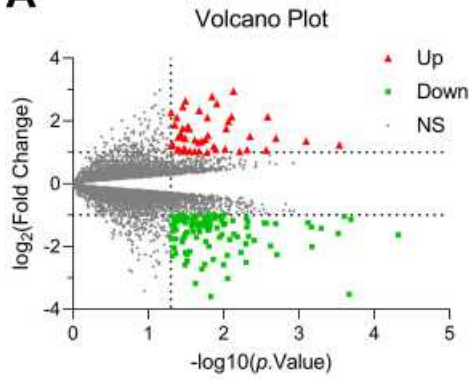

D

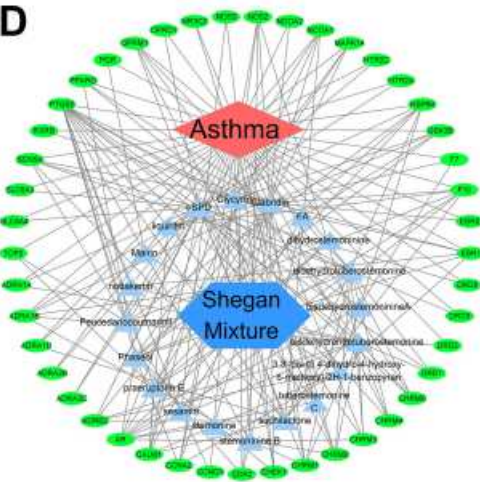

B

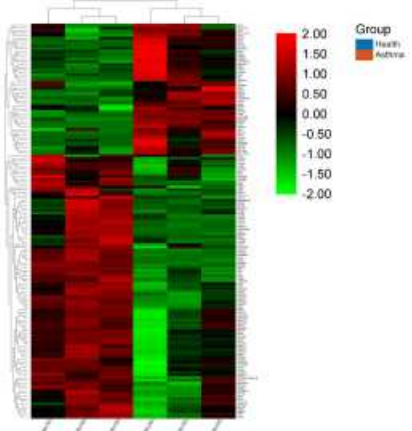

E

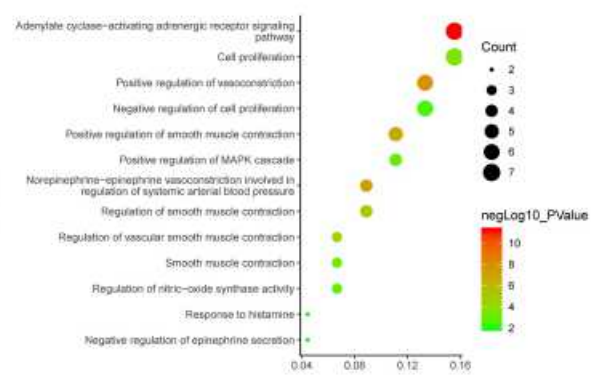

C

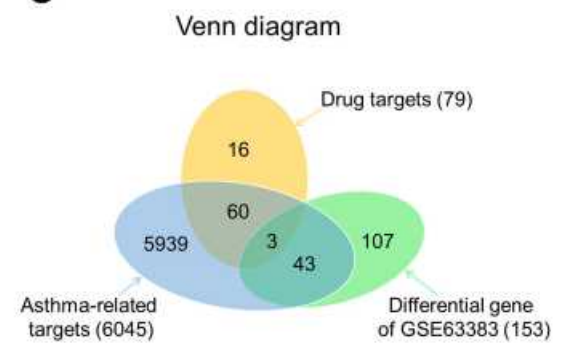

F

Figure 4 Screening and prediction of key ingredients and targets using network pharmacology. (A and B) Heatmap and volcano plot of microarray data GSE35643 from the Gene Expression Omnibus (GEO; http://www.ncbi.nlm.nih.gov/geo/) database. (C) Venn diagram of the target source. (D) Network diagram of ingredients and targets

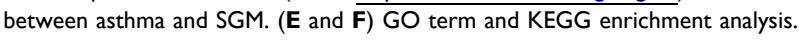

main signal pathways and key proteins in biological functions were identified based on the gene ratio and $p$-value.

\section{Molecular Docking Verification of Key Active Ingredients and Target Interaction}

To verify the reliability of the GO and KEGG enrichment analyses, the software, Discovery Studio 3.0, was used to perform molecular docking of the key active ingredients of SGM and possible therapeutic targets. Briefly, the crystal structures of proteins determined using X-ray crystallography were imported into Discovery Studio 3.0 and docked with ingredients. The results were evaluated by docking parameter $\mathrm{X}_{\text {libdockscore. }}$

\section{Surface Plasmon Resonance (SPR) Assay}

To verify the binding relationship between ingredients and targets, the SPR method was used as previously described. $^{29}$ The PTGS2 protein was immobilized on the surface of CM5 chip by using amine-coupling approach at a flow rate of $10 \mu \mathrm{L} / \mathrm{min}$ in $10 \mathrm{mM}$ sodium acetate buffer ( $\mathrm{pH}$ 5.5). And the chip surface was activated by injecting the mixture of $50 \mathrm{mM}$ N-hydroxysuccinimide (NHS) and $200 \mathrm{mM}$ 1-ethyl3-(3-dimethylaminopropyl) carbodiimide (EDC) for 7 min. After activation, the chip surface was stimulated by injecting $500 \mu \mathrm{g} / \mathrm{mL}$ of PTGS2 protein to reach the target signal level of $5000 \mathrm{RU}$ and was blocked with 1 $\mathrm{M}$ ethanolamine ( $\mathrm{pH}$ 8.5). Then series concentrations of

Table 3 Key Compound-Target Pairs Selected with Molecule Docking

\begin{tabular}{|l|c|c|c|c|}
\hline Target Symbol & Description & PDB Code & Molecule & Libdockscore \\
\hline PTGS2 & Prostaglandin G/H synthase 2 & $5 F 19$ & Bisdehydroneotuber-ostemonine & 109.72 \\
PTGS2 & Prostaglandin G/H synthase 2 & $5 F 19$ & Glabridin & 109.87 \\
HSP90 & Heat shock protein 90 & IOSF & L-SPD & 100.48 \\
FI0 & Coagulation factor X & IEZQ & L-SPD & 108.51 \\
AR & Androgen receptor & IE3G & Glabridin & 111.14 \\
\hline
\end{tabular}


key active ingredient Glabridin, range from $1562.5 \mathrm{nM}$ to $5000 \mathrm{nM}$, were injected into the flow system to test their binding affinities to PTGS2 protein. Finally, the sensor data were fit into an appropriate kinetic binding model to calculate kinetic parameters, such as the dissociation rate constant $(\mathrm{Kd})$, to determine the binding affinity.

\section{Results}

SGM Alleviated Lung Tissue Damage and Inflammatory Response in the Mouse Model of Asthma

To identify the pharmacological effects of SGM in asthma, we used a mouse model of asthma. Our results revealed that compared to the control group, mice in the asthma model group exhibited more obvious lung tissue remodeling, including hyperplasia of the alveoli, compensatory expansion of alveoli, and the infiltration of inflammatory cells. Moreover, inflammatory factors, including IL-4, IL-5, IL-13, and IFN- $\gamma$ were also activated. SGM alleviated lung tissue damage and the levels of inflammatory factors in blood in a dose-dependent manner (Figures 2 and 3).

\section{Identification of Key Active Ingredients in SGM}

In this study, 139 active ingredients were filtered out using TCMSP database (Supplementary Table 1). Among them, 20 active ingredients, which had OB and DL values higher
A

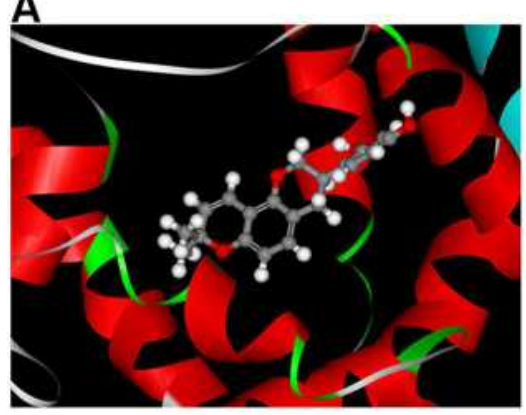

D

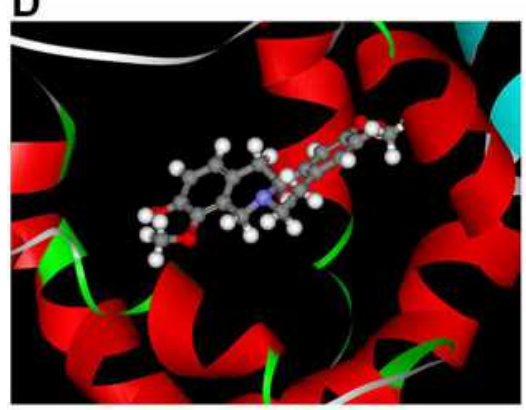

G

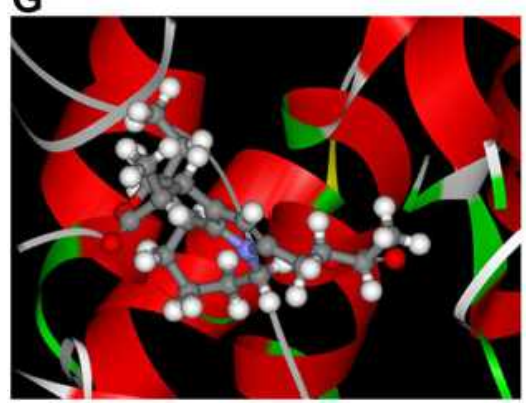

B

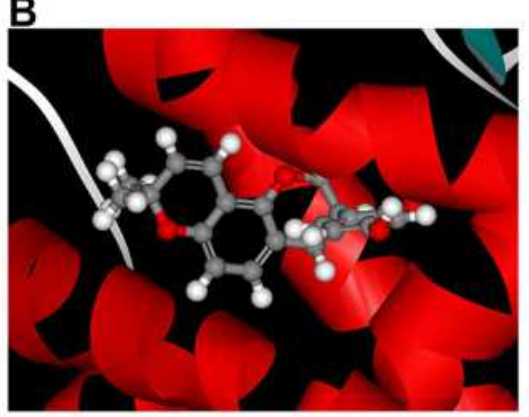

E

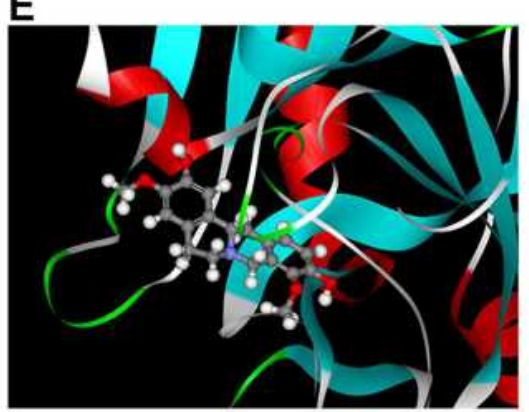

H

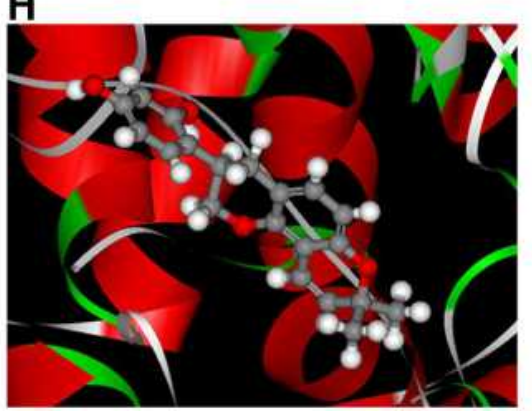

C

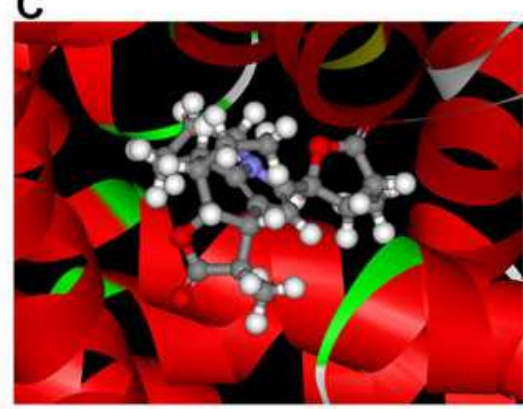

$\mathbf{F}$

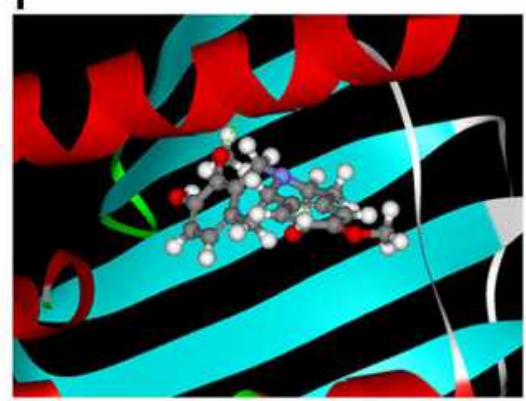

I

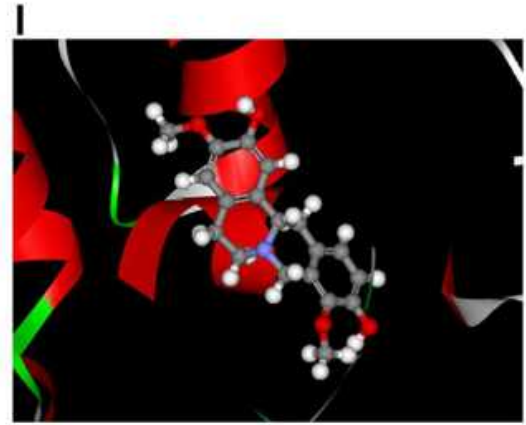

Figure 5 3D molecular docking model of molecule-target pairs. (A) CALMI-glabridin. (B) CALMI-L-SPD. (C) AR-bis. (D) AR-glabridin. (E) FI0-L-SPD. (F) HSP 90-L-SPD. (G) PTGS2-bis. (H) PTGS2-glabridin. (I) PTGS2-L-SPD.

Abbreviation: Bis, bisdehydroneotuberostemonine. 
than the average were considered to be key ingredients.

The details are shown in Table 2.

\section{Targets of Active Ingredients and Asthma Were Determined}

We identified 79 ingredient-related targets in SGM, and some of these ingredients correspond to same targets (Supplementary Table 2). Moreover, a total of 6045 known targets for asthma were collected and 858 DEGs between normal person and asthma patients were extracted from the microarray data GSE35643. These DEGs included 49 up-regulated and 104 downregulated genes as shown in Figure 4A and B. Select processes are shown in Figure 4C. A total of 63 potential targets were identified after the intersection (Supplementary Table 3).

\section{PPI and Ingredient-Target Network Analysis}

PPI were used to identify the primary targets related to asthma and eventually 45 proteins were selected. To filter potential ingredients and related targets, we performed an ingredient-target network analysis. As seen in Figure 4D, in this network, 67 nodes are marked, including 20 compounds and 45 target proteins. Nine molecule-target pairs were outstanding based on the parameter "Neighborhood Connectivity." Bisdehydroneotuberostemonine (160,333-27-7), glabridin, and L-SPD could be the potential ingredients of SGM for asthma.

\section{Enrichment Analysis}

Online GO and KEGG enrichment analyses were performed to determine the primary biological functions and pathways. Results show that the significant functions of SGM in the treatment of asthma were related to cell
A

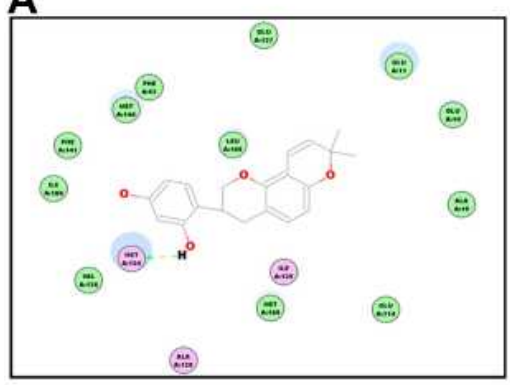

D

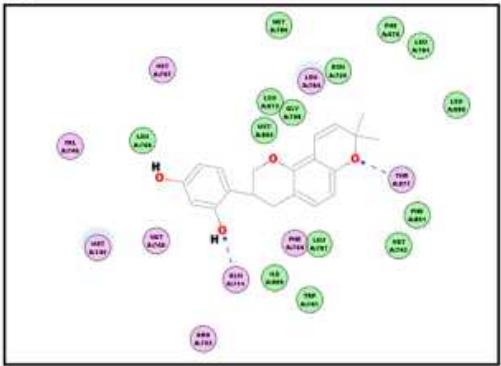

G

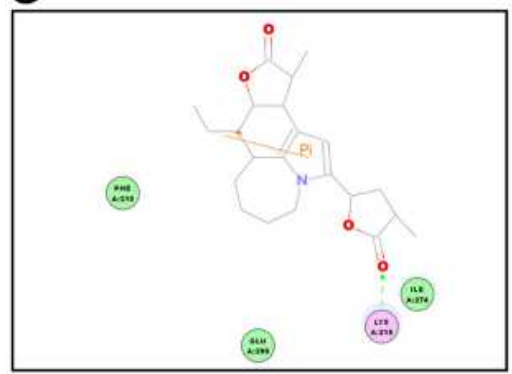

B

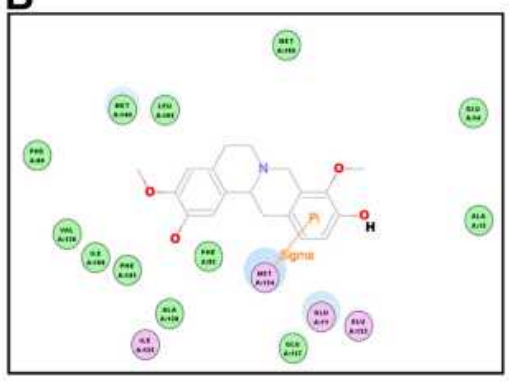

E

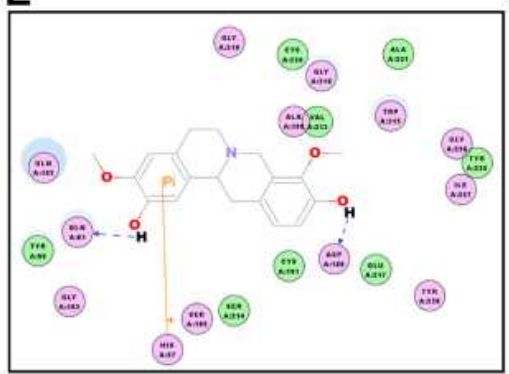

H

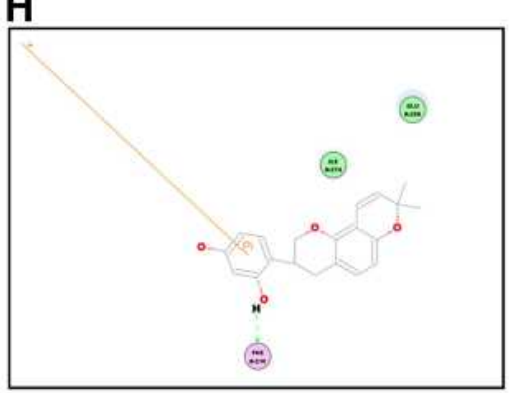

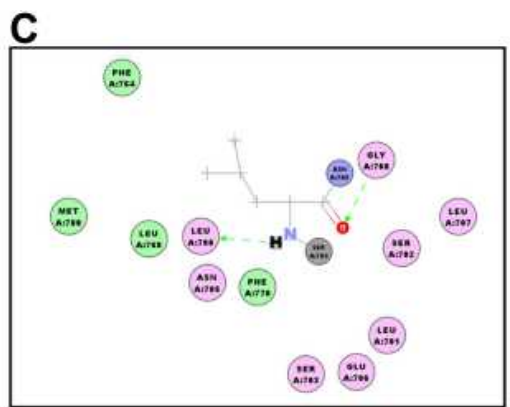

F

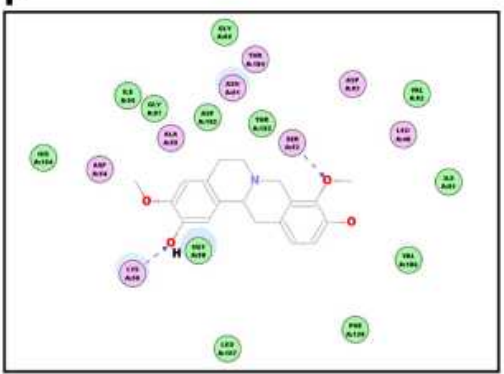

1

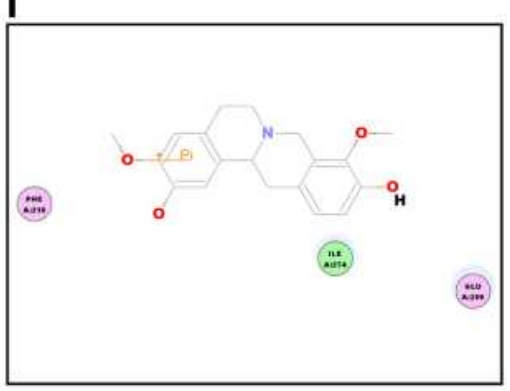

Figure 6 2D molecular docking model of molecule-target pairs. (A) CALMI-glabridin. (B) CALMI-L-SPD. (C) AR-bis. (D) AR-glabridin. (E) FI0-L-SPD. (F) HSP 90-L-SPD. (G) PTGS2-bis. (H) PTGS2-glabridin. (I) PTGS2-L-SPD.

Abbreviation: Bis, bisdehydroneotuberostemonine. 
proliferation and the regulation of smooth muscle contraction, including vasoconstriction and regulation of other substances (such as nitric oxide). The representative GO terms are listed in Figure 4E. The KEGG pathway enrichment analysis concentrated on the regulation of smooth muscle contraction and inflammation, which are shown in Figure 4F.

\section{Molecular Docking}

We performed molecular docking and validated nine molecule-target pairs using Discovery Studio 3.0 software. As a result, five molecule-target pairs, including Bisdehydroneotuberostemonine/PTGS2, Glabridin/PTGS2, L-SPD/HSP90, L-SPD/F10, and Glabridin/AR had a significant binding relationship as their Libdockscore was higher than 100, as shown in Table 3. The 3D and 2D molecule docking images of nine molecule-target pairs are shown in Figures 5 and 6 respectively.

\section{SPR Assay for Glabridin/PTGS2 Molecule-Target Pair}

Among these five molecule-target pairs, glabridin can inhibit cyclooxygenase (COX) and lipoxygenase (LOX), thereby inhibiting the production of inflammatory mediators as well as inflammation, ${ }^{30,31}$ so we chose glabridin/PTGS2 (COX-2) moleculetarget pair for the SPR assay. As shown in Figure 7, series concentrations of the key active ingredient Glabridin, range from $1562.5 \mathrm{nM}$ to $5000 \mathrm{nM}$, were injected to test their binding affinities to PTGS2 protein. After combining the sensor data with a suitable kinetic model, the dissociation rate constant $(\mathrm{Kd})$ is calculated to be equal to $44.5 \mu \mathrm{M}$, which indicated their strong binding affinity.

\section{Discussion}

Asthma is a complex respiratory disease associated with inflammation and contraction of the airway smooth muscle. Drugs approved for use are still limited due to drug tolerance or adverse reactions. SGM is one of the classic TCM designed to relieve bronchospasm and airway inflammation in asthma. However, the mechanism of SGM in asthma is not clear.

Our study revealed the following: 1) SGM reduced lung tissue damage and inflammatory factors, such as IL-4, IL-5, IL-13, and IFN- $\gamma$, in asthma in vivo; 2) 20 ingredients, 45 related proteins, and 5 molecule-target pairs (bisdehydroneotuberostemonine/PTGS2, glabridin/PTGS2, L-SPD/ HSP90, L-SPD/F10, and glabridin/AR) were predicted as
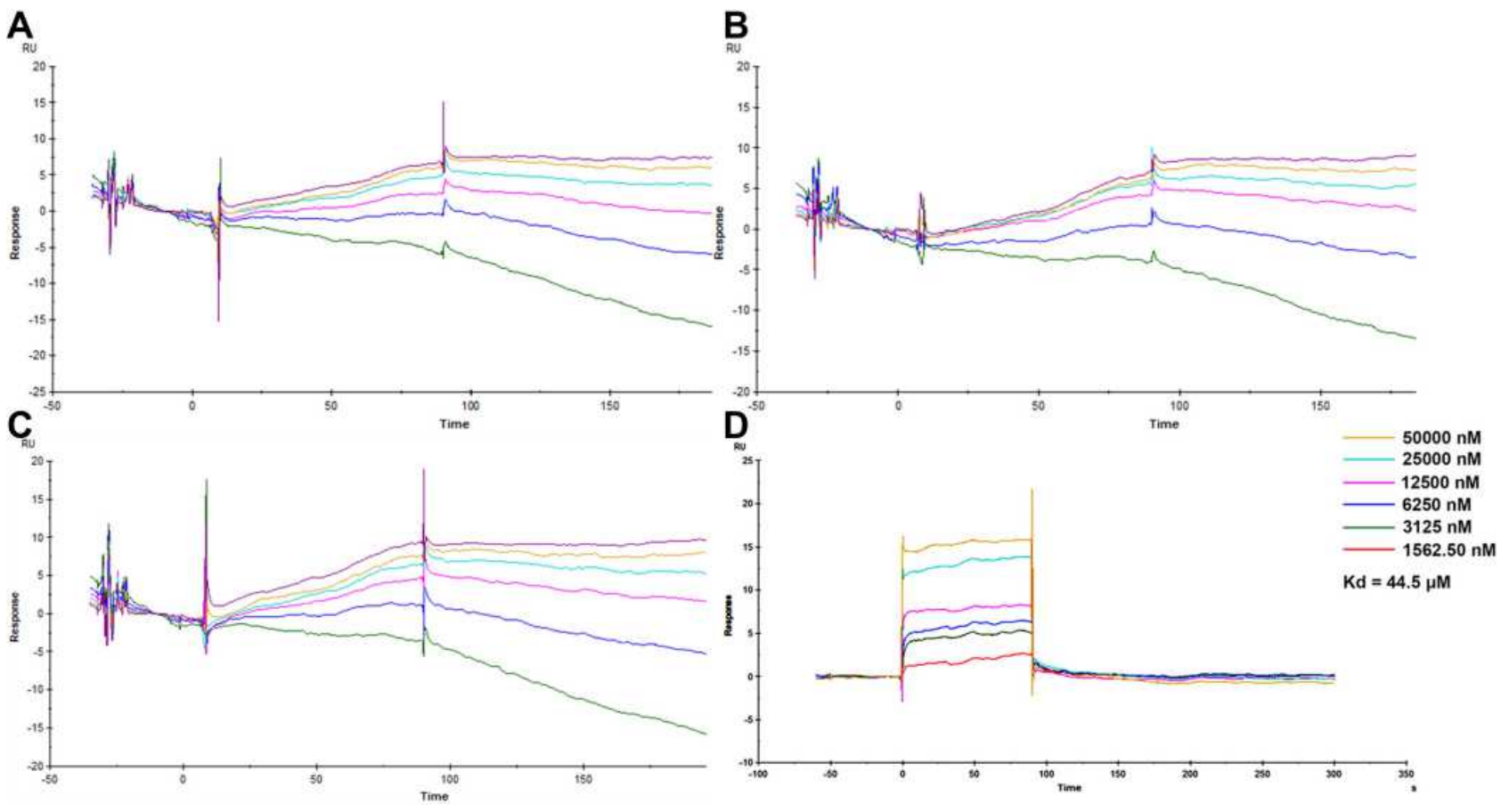

Figure 7 SPR analysis between key ingredients and targets. (A) Binding relationship validation between FI0 and glabridin (A), FI0 and L-SPD (B), AR and glabridin (C), and PTGS2 and glabridin (D) using SPR assay. 
key pharmacological nodes in SGM based on the network pharmacology approach and molecular docking; 3) Inflammatory and smooth muscle related pathway, such as smooth muscle contraction, were considered as the main pharmacological mechanism of SGM in the treatment of asthma; 4) the binding relationship between glabridin and PTGS2 were verified using the SPR assay and Kd was determined to be $44.5 \mu \mathrm{M}$, which indicated their strong binding affinity.

Bronchospasm is the hallmark of asthma and can be induced by the development of airway inflammation. We predicted that SGM mainly participated in pathways related to inflammation and regulation of smooth muscle contraction. Moreover, results from our animal experiments also demonstrated the significant anti-inflammatory action of SGM in asthma, thus indicating that the antiinflammatory effect is one of the protective mechanisms of SGM to alleviate asthma.

In this research, to identify the synergistic action of multiple components, multiple targets, and multiple pathways of SGM, we found 5 key molecule-target pairs (including 3 ingredients and 4 proteins) using network analysis. All these ingredients or proteins have been previously demonstrated to have anti-asthma or antiinflammatory effects. Bisdehydroneotuberostemonine is a natural product obtained from Stemona collinsae. A previous study indicates that Stemona collinsae contains an abundance of inhibitors of leukotriene biosynthesis and can inhibit leukotriene level in an ex vivo test system using activated human neutrophilic granulocytes. ${ }^{32}$ However, the specific biological functions of bisdehydroneotuberostemonine are not clear and could, therefore, be a topic for further study. It has been demonstrated that glabridin has an anti-inflammatory effect in vitro on murine macrophages, ${ }^{33}$ microglia, ${ }^{30}$ and dendritic cells, ${ }^{34}$ as well as in vivo in BDF1 mice. ${ }^{31}$ PTGS2, also known as COX-2, is a typical inflammatory-related enzyme that participates in generating COX products. ${ }^{33}$ This study was also consistent with our prediction that glabridin bound to PTGS2. It has been reported that the phytoestrogen, Glabridin, can bind to the human estrogen receptor in rat uterus. ${ }^{35}$ In addition, similar network pharmacology studies have found that the inhibition of PTGS2 can exert anti-inflammatory and anti-asthmatic effects through the NF-kb signaling pathway. ${ }^{36,37}$ Based on the structure of the hormone, it appears logical that our results could predict the binding relationship between glabridin and the androgen receptor. A previous study reported that L-SPD is a tetrahydroprotoberberine alkaloid that can agitate the dopamine D1 receptor and antagonize the D2 receptor, ${ }^{38,39}$ which has been validated in several models of Alzheimer's disease. ${ }^{40}$ Some investigations have indicated that coagulation factor X (F10) participates in this process and modulates airway remodeling, which might be a regulator for asthma ${ }^{41}$ as well as HSP90, which can activate the prekallikreinkininogen complex in asthma. ${ }^{42}$

Our research findings indicated that SGM had a certain effect in easing lung tissue damage and lowering the level of inflammatory factors. These functions might be the result of the regulation of smooth muscle contraction and inflammation. However, additional welldesigned animal studies, in vitro experimental models, or clinical trials will be needed to further elucidate the mechanism of SGM.

\section{Conclusion}

All in all, using network pharmacology, the multicomponent, multi-target, and multi-mechanism of SGM in asthma were explained. A total of 20 representative ingredients and 63 potential targets were identified and it was revealed that the function of SGM may have been attributed to the regulation of smooth muscle contraction and inflammation. Meanwhile, 5 key molecule-target pairs were screened and our results suggested that glabridin could bind to PTGS2 $(\mathrm{Kd}=44.5 \mu \mathrm{M})$. These binding data could be further explored in future research. Moreover, in vivo data supported the protective role of SGM in lung tissue damage and inflammatory response.

\section{Abbreviations}

SGM, Shegan mixture; TCM, Traditional Chinese medicine; TCMSP, Traditional Chinese Medicine Systems Pharmacology; OB, Oral bioavailability; DL, Druglikeness; SPR, Surface plasmon resonance; DEGs, Differentially expressed genes; PPI, Protein-protein interaction; GO, Gene ontology; KEGG, Kyoto Encyclopedia of Genes and Genomes; IFN- $\gamma$, Interferon gamma; IL, Interleukin; ICSs, Inhaled corticosteroids; ELISA, Enzyme-linked immunosorbent assay; SPF, Specific pathogen free; OVA, Ovalbumin; i.p., Intraperitoneal injection; HBSS, Hanks' balanced salt solution; COX, Cyclooxygenase; LOX, Lipoxygenase; PDB, Protein Data Bank; DXM, Dexamethasone. 


\section{Acknowledgments}

This project was supported by grant from Natural Science Foundation of Shanghai (16401900500) and National Natural Science Foundation of China (81973504).

\section{Author Contributions}

All authors made a significant contribution to the work reported, whether that is in the conception, study design, execution, acquisition of data, analysis and interpretation, or in all these areas; took part in drafting, revising or critically reviewing the article; gave final approval of the version to be published; have agreed on the journal to which the article has been submitted.

\section{Disclosure}

The authors declare no conflicts of interest in this work.

\section{References}

1. Vos T, Abajobir AA, Abate KHet al. Global, regional, and national incidence, prevalence, and years lived with disability for 328 diseases and injuries for 195 countries, 1990-2016: a systematic analysis for the Global Burden of Disease Study 2016. Lancet. 2017;390 (10100):1211-1259.

2. Bateman ED, Hurd SS, Barnes PJ, et al. Global strategy for asthma management and prevention: GINA executive summary. Eur Respir J. 2008;31(1):143-178. doi:10.1183/09031936.00138707

3. Godson C, Phimister EG. Balancing the effect of leukotrienes in asthma. $N$ Engl J Med. 2020;382(15):1472-1475. doi:10.1056/ NEJMcibr2000118

4. Chetta A, Zanini A, Foresi A, et al. Vascular endothelial growth factor up-regulation and bronchial wall remodelling in asthma. Clin Exp Allergy. 2005;35(11):1437-1442. doi:10.1111/j.1365-2222.2005. 02360.x

5. Beasley R, Harper J, Bird G, Maijers I, Weatherall M, Pavord ID. Inhaled corticosteroid therapy in adult asthma. Time for a new therapeutic dose terminology. Am J Respir Crit Care Med. 2019;199 (12):1471-1477. doi:10.1164/rccm.201810-1868CI

6. Gupta RP, Mukherjee M, Sheikh A, Strachan DP. Persistent variations in national asthma mortality. Hospital Admissions and Prevalence by Socioeconomic Status and Region in England, Thorax. 2018;73(8):706-712.

7. Marmot M. Inequalities in asthma mortality: a specific case of a general issue of health inequalities. Thorax. 2018;73(8):704-705. doi:10.1136/thoraxjnl-2018-211573

8. Holm M, Omenaas E, Gíslason T, et al. Remission of asthma: a prospective longitudinal study from northern Europe (RHINE study). Eur Respir J. 2007;30(1):62-65. doi:10.1183/09031936. 00121705

9. Denner DR, Sangwan N, Becker JB, et al. Corticosteroid therapy and airflow obstruction influence the bronchial microbiome, which is distinct from that of bronchoalveolar lavage in asthmatic airways. J Allergy Clin Immunol. 2016;137(5):1398-1405.e3. doi:10.1016/j. jaci.2015.10.017

10. Deykin A, Lazarus SC, Fahy JV, et al. Sputum eosinophil counts predict asthma control after discontinuation of inhaled corticosteroids. J Allergy Clin Immunol. 2005;115(4):720-727. doi:10.1016/j.jaci.2004.12.1129
11. Gauvreau GM, Jordana M, Watson RM, Cockroft DW, O'Byrne PM. Effect of regular inhaled albuterol on allergen-induced late responses and sputum eosinophils in asthmatic subjects. Am J Respir Crit Care Med. 1997;156(6):1738-1745. doi:10.1164/ajrccm.156.6.96-08042

12. Sears MR, Taylor DR, Print CG, et al. Regular inhaled beta-agonist treatment in bronchial asthma. Lancet. 1990;336(8728):1391-1396. doi:10.1016/0140-6736(90)93098-A

13. Sears MR. Worldwide trends in asthma mortality. Bull Int Union Tuberc Lung Dis. 1991;66(2-3):79-83.

14. Pearce N. The use of beta agonists and the risk of death and near death from asthma. $J$ Clin Epidemiol. 2009;62(6):582-587. doi:10.1016/j.jclinepi.2009.01.004

15. Hui D, Yonghong W, Jian Y, et al. Prescriptions from traditional Chinese medicine compared with salbutamol and montelukast for the treatment of pediatric asthma: a randomized controlled trial. $J$ Tradit Chin Med. 2017;37(4):522-529. doi:10.1016/S02546272(17)30159-0

16. Du H, Wang Y, Shi Y, Yu J, Sun W, Zhang Y. Effect of traditional Chinese medicine on inflammatory mediators in pediatric asthma. Mediators Inflamm. 2016;2016:1-6. doi:10.1155/2016/51 43703

17. Wojcikowski K, Gobe G. Animal studies on medicinal herbs: predictability, dose conversion and potential value. Phytother Res. 2014;28(1):22-27. doi:10.1002/ptr.4966

18. Nials AT, Uddin S. Mouse models of allergic asthma: acute and chronic allergen challenge. Dis Model Mech. 2008;1(4-5):213-220. doi: $10.1242 / \mathrm{dmm} .000323$

19. Patel BV, Wilson MR, Takata M. Resolution of acute lung injury and inflammation: a translational mouse model. Eur Respir J. 2012;39 (5):1162-1170. doi:10.1183/09031936.00093911

20. Ru J, Li P, Wang J, et al. TCMSP: a database of systems pharmacology for drug discovery from herbal medicines. J Cheminform. 2014;6 (1):13. doi:10.1186/1758-2946-6-13

21. Niu WH, Wu F, Cao WY, Wu ZG, Chao YC, Liang C. Network pharmacology for the identification of phytochemicals in traditional Chinese medicine for COVID-19 that may regulate interleukin-6. Biosci Rep. 2021;41(1). doi:10.1042/BSR 20202583

22. Xu X, Zhang W, Huang C, et al. A novel chemometric method for the prediction of human oral bioavailability. Int J Mol Sci. 2012;13 (6):6964-6982. doi:10.3390/ijms13066964

23. Wan Y, Xu L, Liu Z, et al. Utilising network pharmacology to explore the underlying mechanism of Wumei Pill in treating pancreatic neoplasms. BMC Complement Altern Med. 2019;19(1):158. doi:10.1186/s12906-019-2580-y

24. Chi Z, Wei G, Ling-Ling S, Han-Rui C, Li-Zhu L. Network pharmacology-based analysis of the mechanism of action of the Herb Pair Chai Hu-Bai Shao. Digital Chin Med. 2019;2 (4):227-236. doi:10.1016/j.dcmed.2020.01.004

25. Yamanishi Y, Kotera M, Kanehisa M, Goto S. Drug-target interaction prediction from chemical, genomic and pharmacological data in an integrated framework. Bioinformatics. 2010;26(12):i246-i254. doi:10.1093/bioinformatics/btq176

26. Pei T, Zheng $C$, Huang $C$, et al. Systematic understanding the mechanisms of vitiligo pathogenesis and its treatment by Qubaibabuqi formula. $J$ Ethnopharmacol. 2016;190:272-287. doi:10.1016/j.jep.2016.06.001

27. Yu M, Song X, Yang W, Li Z, Ma X, Hao C. Identify the key active ingredients and pharmacological mechanisms of compound XiongShao capsule in treating diabetic peripheral neuropathy by network pharmacology approach. Evid Based Complement Alternat Med. 2019;2019:580-1591. doi:10.1155/2019/5801591

28. Franceschini A, Szklarczyk D, Frankild S, et al. STRING v9.1: protein-protein interaction networks, with increased coverage and integration. Nucleic Acids Res. 2013;41(Database issue):D808D815. doi:10.1093/nar/gks1094 
29. Nguyen HH, Park J, Kang S, Kim M. Surface plasmon resonance: a versatile technique for biosensor applications. Sensors. 2015;15 (5):10481-10510. doi:10.3390/s150510481

30. Park SH, Kang JS, Yoon YD, et al. Glabridin inhibits lipopolysaccharide-induced activation of a microglial cell line, BV-2, by blocking NF-kappaB and AP-1. Phytother Res. 2010;24 (Suppl 1):S29-S34. doi:10.1002/ptr.2872

31. Kang JS, Yoon YD, Cho IJ, et al. Glabridin, an isoflavan from licorice root, inhibits inducible nitric-oxide synthase expression and improves survival of mice in experimental model of septic shock. J Pharmacol Exp Ther. 2005;312(3):1187-1194. doi:10.1124/jpet. 104.077107

32. Adams M, Pacher T, Greger H, Bauer R. Inhibition of leukotriene biosynthesis by stilbenoids from Stemona species. J Nat Prod. 2005;68(1):83-85. doi:10.1021/np0497043

33. Chandrasekaran CV, Deepak HB, Thiyagarajan P, et al. Dual inhibitory effect of Glycyrrhiza glabra (GutGard ${ }^{\mathrm{TM}}$ ) on COX and LOX products. Phytomedicine. 2011;18(4):278-284. doi:10.1016/j.phymed.2010. 08.001

34. Kim JY, Kang JS, Kim HM, et al. Inhibition of bone marrow-derived dendritic cell maturation by glabridin. Int Immunopharmacol. 2010;10(10):1185-1193. doi:10.1016/j. intimp.2010.06.025

35. Tamir S, Eizenberg M, Somjen D, et al. Estrogenic and antiproliferative properties of glabridin from licorice in human breast cancer cells. Cancer Res. 2000;60(20):5704-5709.

36. $\mathrm{Lv} \mathrm{X}, \mathrm{Xu} \mathrm{Z}, \mathrm{Xu} \mathrm{G}$, et al. Investigation of the active components and mechanisms of Schisandra chinensis in the treatment of asthma based on a network pharmacology approach and experimental validation. Food Funct. 2020;11(4):3032-3042. doi:10.10 39/D0FO00087F
37. Huang XF, Cheng WB, Jiang Y, et al. A network pharmacology-based strategy for predicting anti-inflammatory targets of ephedra in treating asthma. Int Immunopharmacol. 2020;83: 106423. doi:10.1016/j.intimp.2020.106423

38. Dong ZJ, Guo X, Chen LJ, Han YF, Jin GZ. Dual actions of (-)stepholidine on the dopamine receptor-mediated adenylate cyclase activity in rat corpus striatum. Life Sci. 1997;61(4):465-472. doi:10.1016/S0024-3205(97)00404-9

39. Zou LL, Liu J, Jin GZ. Involvement of receptor reserve in D1 agonistic action of (-)-stepholidine in lesioned rats. Biochem Pharmacol. 1997;54 (2):233-240. doi:10.1016/S0006-2952(97)00153-6

40. Hao JR, Sun N, Lei L, et al. L-Stepholidine rescues memory deficit and synaptic plasticity in models of alzheimer's disease via activating dopamine D1 receptor/PKA signaling pathway. Cell Death Dis. 2015;6(11):e1965. doi:10.1038/cddis.2015.315

41. Shinagawa K, Martin JA, Ploplis VA, Castellino FJ. Coagulation factor Xa modulates airway remodeling in a murine model of asthma. Am J Respir Crit Care Med. 2007;175(2):136-143. doi:10.1164/rccm.200608-1097OC

42. Joseph K, Tholanikunnel BG, Kaplan AP. Heat shock protein 90 catalyzes activation of the prekallikrein-kininogen complex in the absence of factor XII. Proc Natl Acad Sci U S A. 2002;99 (2):896-900. doi:10.1073/pnas.022626899
Drug Design, Development and Therapy

\section{Publish your work in this journal}

Drug Design, Development and Therapy is an international, peerreviewed open-access journal that spans the spectrum of drug design and development through to clinical applications. Clinical outcomes, patient safety, and programs for the development and effective, safe, and sustained use of medicines are a feature of the journal, which has also

\section{Dovepress}

been accepted for indexing on PubMed Central. The manuscript management system is completely online and includes a very quick and fair peer-review system, which is all easy to use. Visit http://www. dovepress.com/testimonials.php to read real quotes from published authors. 